\title{
Horse Racing With Sheep Ankle Bones: The Play of Nomadic Children in Mongolia
}

\author{
Javzandulam Batsaikhan and Candace Kaye
}

\begin{abstract}
Javzandulam Batsaikhan has been an early childhood education lecturer at Mongolian National University of Education, Ulaanbaatar, Mongolia, since 2010. Her focus is teaching action research methodology to undergraduate students. Previously, she taught children of herding families in the Mongolian countryside and worked with a nonprofit educational project that encouraged Mongolian children who had left school to return. She is a doctoral student at New Mexico State University with a major interest in the investigation of early education equity for nomadic children in Mongolia. Email: javzandulam@msue.edu.mn
\end{abstract}

Candace Kaye, $\mathbf{P h D}$, is affiliated graduate faculty at New Mexico State University and visiting scholar and research associate at Mongolian National University of Education (MNUE). Her scholarly involvement with early childhood education in Mongolia began in 1992. Since that time, her collaboration with Mongolian scholars has included serving as the U.S. Fulbright teaching and research scholar in early childhood education in the MNUE School of Preschool Education, foreign consultant for the revision of Mongolian national standards of early childhood, and ongoing visiting consultant, lecturer, and researcher at MNUE. Email: kaye@ nmsu.edu

The play activities of nomadic Mongolian children embrace an ancient traditional philosophy of life, connecting families to nature, respecting elders, and encouraging tenacity in daily life. This article discusses the context of this unique form of child play, its meaning, and its functional value. The major focus is on how these play activities have been communicated through centuries within themes of survival, lifestyle, and story. The article first reviews the cultural concept of play within discussions of adaptation, evolutionary process, and a culturespecific phenomenon, proceeds to examine how Mongolian traditional play encourages young children to be knowledgeable about nomadic values, and concludes with a discussion of how the context of the play of Mongolian nomadic children is situated within an understanding the concept of the ludic.

Key words: culture; children; play; Mongolia; nomads connection to the nomadic lifestyle. She is currently conducting a longitudinal study concerning equity of access for young nomadic children to educational opportunities. The second author, a United States professor, has studied early childhood education in Mongolia since the first reforms in the 1990s after Mongolia became a democratic nation. Both authors continue to have numerous opportunities to explore and record the traditional learning of
Mongolian culture and history has been formed, in large part, by the dynamic forces of nature and the challenges of daily life as embodied in the ancient nomadic existence of the Mongol peoples. Specifically, the culture and society of Mongolia is greatly influenced by the central role of nomadism, which remains the way of life for more than one-quarter $(986,721)$ of the country's 3,063,568 people (National Statistical Office of Mongolia, 2016). Mongolia is one of the last nations in the world to have such a high proportion of nomadic citizens.

With the collapse of the USSR and thereby the Sovietinspired socialist educational system in Mongolia in the early 1990s, the country underwent a change from a socialist to a democratic government, which in turn led to the opening of the nation to international educational practices as well as an ongoing commitment to democratic and human freedoms. Since that time, the principles and policies of education continue to be revised and reformed.

Amid these fundamental changes, research into longstanding cultural learning methods, ethics, and manners based on daily practice within the nomadic lifestyle has been limited. To begin to fill that void, as a Mongolian, the first author has a personal and scholarly 
nomadic children through their daily practices.

As in all cultures, the lifestyle of Mongolia's nomadic children is reflected in the content of their play activitiesdeveloped centuries ago by their forefathers, not just to educate their young children, but also to protect them and preserve their cultural heritage (Daariimaa, 2011). As an endorsement of these nomadic play activities, today Mongolian traditional play is strongly encouraged by Mongolia's national early childhood learning standards (Mongolian Ministry of Education, Culture and Science, 2013, 2014) and, as a result, may be observed in both public and private early childhood programs in the countryside as well as in the cities.

The premise of this article, therefore, is that the play activities of contemporary Mongolian children reflect their cultural heritage by embracing the ancient nomadic philosophy of life, a strongly held foundation for this still young democratic nation.

\section{Play and Culture}

Within the field of early childhood education and child development, many definitions and claims have been proposed with regard to the essential role of play for child development within cultural contexts. As such, children's play has long been recognized as an important contributor to children's development and learning (Hyun, 1998), and play has been viewed as an acculturative mechanism (Schwartzman, 1978), meaning that, through play, "children learn societal roles, norms, and values" (Roopnarine, Johnson, \& Hooper, 1994, p. 31).

The following discussion challenges the notion of a universal definition of play, proposing the addition to traditional definitions of play of specific connections of play to the cultural consideration of adaptation, evolution, and a specific cultural environment. Based on a review of the literature, the following three themes are emphasized: (a) limits of a universal notion of child's play, (b) cultural concepts of play, and (c) universal play theory vs. the influence of cultural environments on play.

\section{Limits of a Universal Conventional Notion of Child's Play}

While there is tacit agreement among early childhood educators that the values of play are culturally contextualized, researchers such as Hyun (1998) have noted that studies about child's play and subsequent approaches to understanding child's play (Howes, 1980; Howes, Unger, \& Seider, 1989; Parten, 1932) have been based mainly on cultural perspectives, variously called "Western middle-class, European, or Euro-American perspective" (p. 79). Indeed, Roopnarine and Johnson (1994) posited that Euro-American mainstream ideas about play and early childhood education cannot include specific cultural understandings. As a result, Hyun (1998) maintained that "exploring and creating new understandings of child's play, deconstructing a universal conventional orientation of child's play in developmental processes, and developing culturally relevant frames of reference for understanding child's play are urgent tasks for early childhood practitioners and families" (p. 92).

\section{Cultural Concepts of Play}

According to several researchers and educators, understanding the specific and distinct cultural constructs of play is important for understanding development within cultures (Roopnarine \& Johnson, 1994). According to Hyun (1998), for example,

we all have a culturally shaped frame of mind set. This culturally grounded phenomenon tends to lead people to believe that their ways of looking at things are universally acceptable, which may not be true. Thus, we all can become culturally blind. (p. 81) 


\section{Universal Play Theory vs. the Influence of Cultural Environments on Play}

For more than 60 years, researchers in early childhood education have relied primarily on Parten's (1932) and Howes's (1980) conventional theories when deconstructing child development through play. Increasingly, however, conclusions drawn from these two theories are not considered acceptable for validating a universal theory of play and development (Hughes, 2009). For example, contradicting Parten's theory of cooperative play beginning in the preschool years, toddlers have been observed to play cooperatively already at 18 months in some specific cultural settings (Brenner \& Mueller, 1982; Howes \& Matheson, 1992). Additionally, within some sociocultural contexts, cooperative social interaction "is pervasive in the family culture" (Hyun, 1998, p. 102).

Similarly, later in this article, nomadic families Mongolia are viewed as having such a highly involved interactive social system. The implied understanding of becoming a "cooperative player," according to Hyun (1998), is as follows:

- Within a multi-generational and multi-age family environment, developing that kind of sociocognitive schema may be an inevitable developmental phenomenon. In this cultural context, the young child may first explore more about others than about self.

- Mentally visualizing play with others, observing others' intercommunicative expressions, being aware of the existence of family members or others in a play context are common phenomena that the young child has been receiving even since birth.

- Thus, physically visualizing and cognitively realizing others during the early periods of childhood may be more apparent than the realizing of self as a single organism in such a child's developmental changes.

Thus, if we follow Parten's theory, we may continuously underestimate or misunderstand the diverse young child's developmental abilities and potentials. More critically, we may be using some limited or culturally blind hypotheses to interpret the child's developmental changes and play behaviors. (pp. 22-23)

\section{Culture and the Play Framework Underlying This Article}

The following discussion describes three major contributions of play within specific cultural environments: (a) supporting adaptive behaviours necessary for survival and social change (survival), (b) contributing to the dynamics of human evolution (lifestyle), and (c) offering opportunities to recreate the cultural environment (story).

\section{Survival: The Role of Play in Supporting Adaptive Behaviours Within Cultural Contexts}

Bergen (2014) noted that since ancient times, play has been a means for humans to survive the many uncertainties they have faced based on the fact that the most playful humans continue to be those who demonstrate the greatest range of adaptive behaviours as environments or social conditions change.

Defining adaptive behaviours in play within cultural contexts. In early childhood, emerging adaptive skills are usually defined within the broad categories of motor skills, communication, personal care, and social behaviour.

Adaptive behaviour is generally evaluated on the basis of positive achievements presented within developmental tasks (Masten, 2001), described by McCormick, Kuo, and Masten (2011) as psychosocial or physical milestones and accomplishments expected for individuals in a given period of development within specific sociocultural 
contexts. However, these same researchers have noted that, at the same time, some of these developmental tasks are viewed as universal, such as learning to walk or talk, whereas others are common within developed nations, such as learning to read, while others are more specific to a given culture or context, such as learning to weave textiles, fishing, mastering sacred texts or, in the case of nomadic children, herding.

More recently, Masten and Monn (2015) pointed to the importance of child and family resilience as an important consideration in contemporary discussions of adaptive behaviour. However, a review of the literature indicates few efforts to date to systematically integrate the theory, findings, and implications of these two areas.

In her studies of "the ordinariness of resilience" Masten (2001, p. 227) found that resilience is common and that it usually arises from the normative functions of human adaptational systems, with the greatest threats to human development, therefore, being those that compromise the adaptive systems. It could be argued that this threat could include the steppes of Mongolia, especially in the event of a $z u d$-the Mongolian term for a severe winter where large numbers of livestock die. This natural disaster is considered unique to Mongolia (Sternberg, 2010), where one half of the population depends entirely on pastoral farming (Jacobs, 2010).

\section{Lifestyle: The Role of Play as an Evolutionary Contribution}

From another perspective on play, Roopnarine et al. (1994) maintained that play is biologically based, kept alive as an evolutionary contribution to human development and changes. Hyun (1998, pp. 23-24) agreed, noting that although play can be defined in several ways, it is essentially a daily activity of children in all cultures.

Considering how young children use play to sample their environment as a means of developing adaptive behaviours, Pellegrini, Dupuis, and Smith (2007) went on to speculate that innovative behaviours developed in play in response to environmental novelty within culture may influence subsequent evolutionary processes. Specifically, they posited that (a) play during this period of immaturity is especially important in the processes of development and evolution, because during ludic play, new strategies and behaviours can be developed at minimal cost, and these strategies, in turn, can influence evolutionary processes; and (b) play influences these processes by supporting the development of new strategies in novel environments during the juvenile period.

\section{Story: The Role of Play as a Reflection of Cultural Environment}

The connection between play and culture has received notable recognition for decades. According to Gosso and Carvalho (2013), "children at play reproduce and also recreate the specificities of their cultural environment" (p. 1). Further, Huizinga (1955) found that play is present everywhere as a well-defined quality of action, which is different from "ordinary" life (p. 117). Lancy (2001) adhered to the theories of Sutton-Smith (2001, 2009), considering play as reflecting cultural mastery. This, in turn, demonstrates a relationship with cultural values that guide and shape play expressions as narratives of daily life are interpreted and attitudes toward play are continually formed. Additionally, Roopnarine et al. (1994) emphasized the importance of calling attention to cultural variability in children's play and pointed to the misinformation that emerges from applying Western values and play analysis to non-Western settings.

\section{Play Activities of Mongolian Nomadic Children}

The major focus of this section is how play activities have been communicated to children throughout the centuries within the themes of survival (adaptive behaviour), lifestyle (evolutionary contribution), and story (interpreting daily life). 


\section{Survival}

Considering the climatic conditions in Mongolia, especially during winter, a nomadic lifestyle may seem very rough. However, over the centuries, Mongolians have developed the qualities of strength and resilience that are essential for surviving in this harsh natural environment.

Nevertheless, in recent years, the number of nomads in Mongolia has decreased significantly as many have moved to the capital city of Ulaanbaatar in search of subsistence or attracted by the perceived advantages and comforts of urban life. In particular, in recent extra-harsh winters, many nomadic families lost their herds-the source of their livelihood-resulting in large rural-to-urban migration, especially from the west of the country, of both nomadic herders and stockbreeders.

Traditionally, Mongolian nomads have raised five species of livestock: horses, cattle, sheep, goats, and camels. In addition, reindeer are raised by the Dukha people known as Tsaatan, who live in the northwest areas around Lake Khovsgol on the border between Mongolia and Siberia. Among their traditional herds, the horse is the mainstay of the Mongolian nomads. A special breed of small Mongolian horses is incredibly hardy. They live all year in semiwild herds, gathered only by nomads for selling or trading and tended by herdsmen in the winter to defend against wolf packs.

Nomad families consider themselves an integral part of nature. As a result, nomadic daily life for young children in the countryside of Mongolia focuses on developing knowledge and skills necessary for existence within the harsh natural environment while still demonstrating respect for this environment. This informal early education is obtained through observation, collaboration, and involvement in activities necessary for survival (Jadambaa, 2010). For example, as part of a belief in the importance of living collaboratively with nature and surviving in the harsh conditions of the Mongolian countryside, children are taught from an early age to respect and protect the natural environment with all their actions (Bujidmaa, 2001).

As two of their first play activities of survival, young children are regularly asked to find dried cow patties to be used for fires and to learn to manipulate the bones of animals in games rather than relying on commercial toys. Playing with stones and becoming adept at their use supports the process of learning the nomadic activities of hunting and protecting oneself from predators.

\section{Lifestyle}

Mongolian nomadic herders' lives are deeply connected to nature and their animals. To understand nature, an animal herder must be continuously observant of the surroundings and the animals cared for-two actions that are strongly encouraged, beginning at an early age.

To train nomadic children, the family elders first assign them small jobs that are deemed appropriate for the early years. For example, children who are five years old begin to take care of lambs. Six-year-olds take care of calves, seven- and eight-year-olds take care of young camels, and nine- to 15-year-olds are considered be able to shepherd and be responsible for a herd of livestock.

Taking care of the animals includes giving them water and food, keeping them warm, and guiding them to appropriate pasture. In other words, young children learn daily herdsmen responsibilities as part of their daily activities at an increasingly more responsible rate.

Additionally, traditional Mongolian teaching emphasizes the following areas: 
- observing and moving confidently within the natural environment

- taking care of one's own family members' health

- participating in the nomadic work ethic

- showing love and respect for nature and the animals cared for by the family

- offering respect for elders.

The horse as a friend. Any nomad can ride as well as they can walk or run. In their daily lives, Mongolians consider the horse as a friend. As a result, there are many songs, poems, praises, proverbs, and sayings about horses, and the Mongolian language includes more than 500 adjectives to express the presence of the horse (Munkhtur, 2007).

The following poem on a subject dear to the heart of most Mongolians-horses-is part of that tradition.

The stories of my people soar with horses,

With wings they reach the golden sun.

The wind riffs through their untrimmed manes,

And, down the skyroad of Khormast,

They return to the lake like migrating birds,

According to the customs of the golden earth.

The poems of the elders soar with horses,

With wings they reach the vibrant stars.

From the herds of letters formed within the month,

We have taken these migrating steeds.

And, from the hitching posts of our poets' horses,

We have taken off for distant roads.

My horse, fly high, oh my horse.

By Ochirkhuu, translated by Simon Wickham-Smith (2006)

Not surprisingly, a large portion of Mongolian nomad child's play is based on the nomads' daily transportation on horseback, and more than 80 of these play activities involve sheep ankle bones (Namjil, 2014). The most common games with sheep ankle bones represent relationships, not only to horses, but to camels, sheep, and goats-the primary animal herds in nomadic families.

"Shagaa." The ankle (shagaa) is a four-sided small bone in the hind legs of sheep, camels, cows, deer, and goats. Each side represents a nomadic herding animal based on its shape:

- dome-shaped side is sheep

- alcove-shaped side is goat

- horsehair shaped side is horse

- inverse-shaped side is camel 


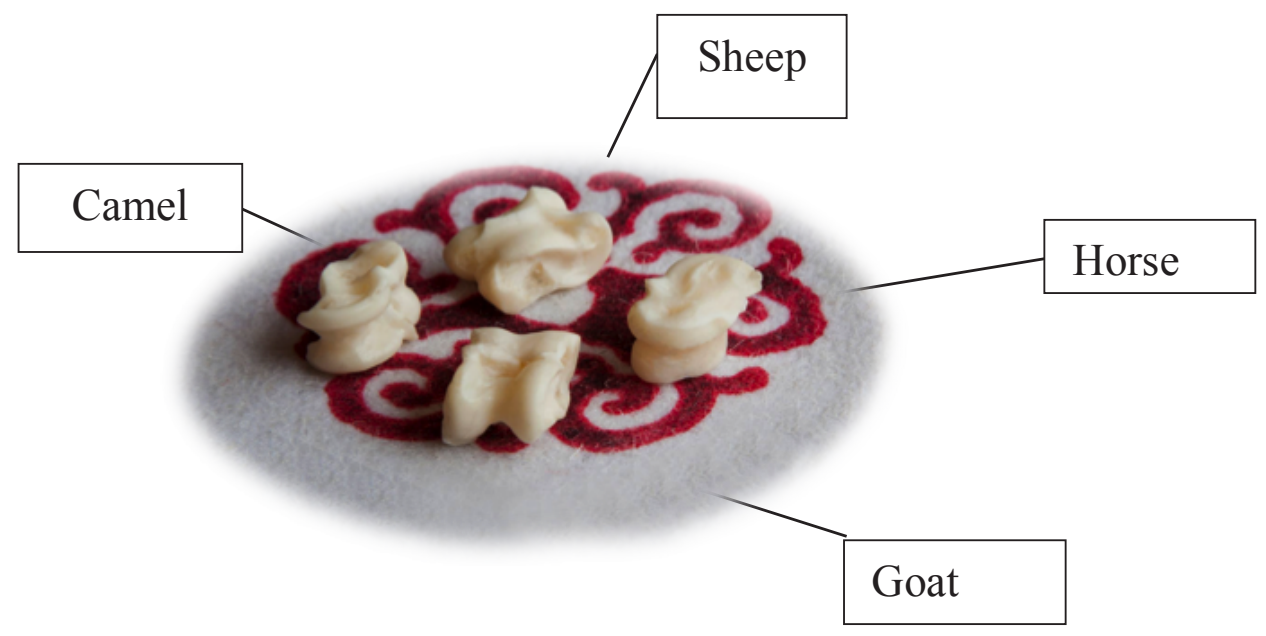

Horse racing with anklebones. Horse racing is one of the Three Manly Games (eriin gurvan naadam) of the annual Naadam Festival, the centuries-old traditional annual summer festival of the nomads; the other two games are wrestling and archery. Since 2010, sheep ankle flipping has been included in Naadam.

Beginning at age 3, horse racing with sheep ankle bones is one of the most common play activities among Mongolian nomadic children. Ankle bone play was first mentioned in The Secret History of the Mongols (Sumyabaatar, 1990) and another book written originally on stone 8,000 years ago. Play used to be called chiga and chigai. Scholars (Gereltuya, 2011) explaining the origin and meaning of the word chiga note that chi means "phenomenal" and gaa means "a thing"; therefore, they propose that shagaa meant "phenomenal thing" in the ancient Mongolian language.

The game involves two or more children, who act as horse race trainers. First, the race horse trainers select their horse (from their shagaa, sheep ankle bone, collection) from their herd of horses. Then the children create long lines with sheep ankle bones to serve as the racecourse, measuring distance and lining up their horses to prepare them to race. The horse race trainers throw four ankle bones in turn and move their horses forward along the racecourse, with the number of horse sides turned up in their toss indicating how many racecourse distances they can advance (Onishon Kindergarten, 2013). At the finish line, the horse-sided ankle bone that reaches the finish line first is the winner of the race. Similar to the real horse races, children sing songs praising the winning ankle bone horse at the end of the play. In addition to the immediate enjoyment of playing, this game encourages children to keep the traditional horse racing culture of Mongolian nomads.

Ankle bone (shagaa) play in contemporary early childhood education curriculum. The Mongolian early childhood core curriculum encourages and supports collaboration among parents, teachers, and researchers toward the goal of rearing healthy children and providing opportunities for children to develop through their own individuality and creative actions (Mongolian Department of Education, Culture and Science, 2014). To that end, one of the most common free play activities in Mongolian kindergartens today continues to be play with sheep ankle bones (shagaa), as illustrated by the following list of the names of plays/activities with ankle bones, by age, in the Mongolian kindergarten curriculum. Play becomes more complex as the children grow, although children of any age can play. 
Age 2:

- Recognize four sides of the ankle bone and grab it.

- Count the number of ankle bones for each animal.

Age 3:

- Play durvun berkh - a four-ankle bone game (durvun berkh means four hardships in Mongolian). Rolling all four sides of the ankle bone on one throw is considered indicative of very good fortune.

- Learn shapes and numbers of each animal ankle bone.

Age 4:

- Play horse racing with ankle bones.

- Play camel racing with ankle bones.

Age 5:

- Crush two ankle bones together. The player who can crush the ankle bones gets to pick one of the ankle bones. The winner is the one who gathers the most ankle bones.

- Guess ankle bone shape by touch.

- Create multicoloured turtles with multicoloured ankle bones. It is one of the most common play activities during national celebrations with friends and family members.

- Collect camel-shaped ankle bones.

Ulziisuren (2011) found that playing games resulted in improved eye sight, learning to sit or read for an extended period of time, perseverance, being both a good winner and a good loser, respect for other players and the rules of games, and increased perceptivity and speed.

Therefore, Gereltuya (2011) concluded that ankle bone play (a) supports young children's development in various ways, including comparing, grouping, recognizing colours, counting, controlling one's behaviour, collaborating with other children, team work, and waiting for others; (b) has a positive impact on eye-hand coordination, which is helpful for school readiness; and (c) not only maintains cultural heritage, but also supports understanding and implementation of rules and mutual communication, speaking skills that prepare children for future learning.

\section{Story}

With regard to the third theme, story, Mongolian oral literature (ardiin aman zohiol) has played a significant role in preserving the country's intellectual heritage for the younger generations. The main types of oral literature are 
tales, riddles, blessings, praises, and Three of the World.

Tales (ulger, domog). These refer to narratives that contain fantasy, problem solving in daily life, and explanations of issues encountered in nomadic society. As such, the ancient Mongolians told the younger generation stories to express their philosophy of life.

Riddles (onisogo). Riddles are a type of oral poem used to challenge thinking and intelligence based on a problem that expresses an incident in a sarcastic way.

Blessings (yeruul). Blessings are special poems related to civic or public ceremonies that bestow goodness and well-being in the future for such events as a wedding, new deel (a traditional costume for both men and women), or a new ger, the Three Manly Games of Naadam (the 800-year-old annual national festival), wool making, a new baby, and birthday celebrations. Nomadic children are blessed when they wear their first deel at a very young age; however, they learn to bless others' new deels by 3 years old.

Praises (magtaal). Praises recognize goodness and accomplishments in the following three areas:

- Ritual praise: Praise for horse race winner, archery, young horse, and Mongolian herd animals (camels, cattle, horses, sheep, goats).

- Praise for mountains and rivers: Altai praise, Khnagai, Khentii, Ihkh Bogd, Gurvan Saikhan, Gobi, Ulaanbaatar, and Khan Khukhii.

- Praises related to the way of life: hunter's praise; Mongolian herd animals' praise, praise for camel, praise for horse. Most young children's first praise will be a compliment for his or her first horse.

Three of the World (yertuntsiin gyrav). This is a harmonious poem about three common characteristics that express philosophic conclusions from natural phenomena, life, historical events, and so on. Here are some examples of Three of the World poems that are commonly introduced to nomadic children between the ages of 3 and 5 :

The three "fars"

Far is the destination for a tired horse

Far is the friend for an unsocial person

Far is the day's end for a hungry man

Three white things

White teeth has a young man

White hair-an old man

White bones-a dead man 


\section{A Theoretical Framework for Examining the Play Activities of Nomadic Children in Mongolia}

The theoretical framework for this discussion of the play activities of nomadic children in Mongolia is based on the following assumptions:

- Play is biologically based and can be examined as a dynamic force that makes an evolutionary contribution to human development (Roopnarine \& Johnson, 1994; Schwartzman, 1978).

- Although there are numerous definitions of play, it is generally agreed that play is a dominant activity of children's daily life in all cultures. Children's play portrays and reflects their social values and family ethnic practices (Hyun, 1998).

- Children play out personally meaningful experiences within a specific sociocultural environment (Erikson, 1963; Vygotsky, 1977).

- Play can be considered an expression of a specific culture and is an important context for cultural learning, an indicator of developmental changes, and a reflection of experience (Schwartzman, 1978).

- Culture is the major contextual influence enacted in all forms of adult-child, child-child, and child-children play (Hyun, 1998).

Despite these widely held assumptions, Gaskins and Miller (2009) noted the absence of an overarching equitable treatment of the role of culture in understanding play. As a result, these researchers voiced their support for the criticism that Western thinking and Western-European children are the standard in play research, noting that this position is responsible for the scant literature on studies that examine the influence of culture on play (see also Holmes, 2013).

After introducing the cultural play world of the young child in the nomadic culture of Mongolia, this discussion examined the connections between the following contributions of play within the nomadic environment:

Adaptive Behaviour Play as Survival Play for Nomadic Children

The conclusion that resilience is the result of ordinary rather than extraordinary processes offers a more positive outlook on human development and adaptation, as well as a direction for policy and practice and specific studies of culture, play, and adaptive behaviours. As such, the study of the role of resilience in development has overturned many negative assumptions and deficitfocused models about children growing up in non-normative societies, such as nomadic ways of life in Mongolia (Engle, Castle, \& Menon, 1996; Fleming \& Ledogar, 2008; Gunnestad, 2006; Turner, Davidson-Hunt, \& O'Flaherty, 2003; Ungar, 2008).

Evolutionary Play as Lifestyle Play for Nomadic Children

Nielson (2012), along with Pellegrini et al. (2007), argued that children's play is critical to the evolution of the human cultural mind.

Cultural Play as Story Play for Nomadic Children

As Lancy (2002) and Gosso (2010) noted, children worldwide engage in playful activities, 
including practicing narratives and engaging in cultural games. Through such activities, children practice their understanding of cultural values, skills, and abilities that are embedded in their everyday experiences.

Turkle (2007) wrote: "We think with the objects we love; we love the objects we think with" (p. 6). The play activities of contemporary Mongolian children reflect a cultural heritage by embracing the ancient nomadic philosophy of life, which deeply connects the people with gratitude to nature, herding animals, hunting, respecting elders, and encouraging tenacity (Tegshjargal, 2014). That is, through play, nomadic children in Mongolia discover the characteristics of the natural environment, relationship to culture, and creative responses to daily challenges (Gereltuya, 2010). Thus, in addition to providing fun and enjoyment, Mongolian child play is a tool for teaching cultural values, including nomadic philosophy, as well as everyday problem-solving skills, and provides the building blocks with which children rehearse, maintain, and build on the institutional realities that reflect cultural practices.

\section{Conclusion}

As illustrated throughout this article, Mongolian traditional play is the main way by which young children are encouraged to be knowledgeable about nomadic values while engaging in both the creative and cultural functions of child play. As Hyun (1998) noted,

we all have a culturally shaped frame of mind set. This culturally grounded phenomenon tends to lead people to believe that their ways of looking at things are universally acceptable, which may not be true. Thus, we all can become culturally blind. (p. 81)

Whether or not cultures acknowledge, condone, support, and set aside time for play, children worldwide engage in playful activities (Gosso, 2010; Lancy, 2002). Nevertheless, there is cultural variability in play (Lancy, 2007), and empirical evidence clearly supports a relationship between play and culture (Göncü \& Gaskins, 2006; Holmes, 2013). Playing with the ankle bones of sheep, as discussed here, reflects the universal functions of play: (a) supporting adaptive behaviours necessary for survival and social changes, (b) contributing to the dynamics of human evolution, and (c) allowing opportunities to recreate the cultural environment. Thus, in considering the ludic quality of the play of the nomadic children of Mongolia, we see that play is not only a cultural force, but also shares in the universal understanding of what the play of childhood is all about. That is, in their play, these children acquire cultural values, skills, and abilities, which are embedded in their everyday experiences. Citing Turkle (2007), "We think with the objects we love; we love the objects we think with" (p. 6). Examining the play of nomadic children in Mongolia reminds us that the landscape of play resides in the specific countryside of daily life.

\section{References}

Bergen, D. (2014). Foundations of play theory. In L. Brooker, S. Edwards, \& M. Blaise (Eds.), Handbook of play and learning in early childhood (pp. 9-20). New York, NY: SAGE.

Brenner, J., \& Mueller, E. (1982). Shared meaning in boy toddlers' peer relations. Child Development, 53(2), 380-391. doi: 10.2307/1128980

Bujidmaa, Ts. (2001). Study of Mongolian educational philosophical development. Ulaanbaatar, Mongolia: State Press.

Daariimaa, G. (2011). Investigating Mongolian insights of bringing up young children. Lavai, 6, 131-133.

Engle, P. L., Castle, S., \& Menon, P. (1996). Child development: Vulnerability and resilience. Social Science \& Medicine, $43(5), 621-635$.

Erikson, E. H. (1963). Childhood and society (rev. ed.). New York, NY: Norton. 
Fleming, J., \& Ledogar, R. J. (2008). Resilience, an evolving concept: A review of literature relevant to Aboriginal research. Pimatisiwin, 6(2), 7-23. Retrieved from: http://pubmedcentralcanada.ca/pmcc/articles/PMC2956753/

Gaskins, S., \& Miller, P. J. (2009). The cultural roles of emotions in pretend play. In C. D. Clark (Ed.), Transactions at play (pp. 5-21). Lanham, MD: University Press of America.

Gereltuya, T. (2011). Impact of Mongolian play on child development. Intellectual Guide, 5, 63-66.

Göncü, A., \& Gaskins, S. (2006). An integrative perspective on play and development. In A. Göncü \& S. Gaskins (Eds.), Play and development: Evolutionary, sociocultural, and functional perspectives (pp. 3-17). New York, NY: Taylor \& Francis.

Gosso, Y. (2010). Play in different cultures. In P. K. Smith (Ed.), Children and play (pp. 80-98). New York, NY: J. Wiley.

Gosso, Y., \& Carvalho, A.M.A. (2013). Play and cultural context. In P. K. Smith (Ed.), Encyclopedia on early childhood development. Retrieved from: http://www.child-encyclopedia.com/play/according-experts/play-and-cultural-context.

Gunnestad, A. (2006). Resilience in a cross-cultural perspective: How resilience is generated in different cultures. Journal of Intercultural Communication, 11. Retrieved from: https://www.immi.se/intercultural/nr11/gunnestad.htm

Holmes, R. M. (2013). Children's play and culture. Scholarpedia, 8(6), 310-316. Retrieved from: http://www.scholarpedia.org/article/ Children\%27s_play_and_culture

Howes, C. (1980). Peer play scale as an index of complexity of peer interaction. Developmental Psychology, 16(4), 371-372. doi: 10.1037/0012-1649.16.4.371

Howes, C., \& Matheson, C. C. (1992). Sequences in the development of competent play with peers: Social and social pretend play. Developmental Psychology, 28(5), 961-974. doi: 10.1037/0012-1649.28.5.961

Howes, C., Unger, O., \& Seider, L. B. (1989). Social pretend play in toddlers: Parallels between social and with solitary pretend. Child Development, 60, 77-84.

Hughes, F. P. (Ed.). (2009). Children, play, and development. Thousand Oaks, CA: SAGE.

Huizinga, J. (1955). Homo ludens; A study of the play-element in culture. Boston, MA: Beacon.

Hyun, E. (1998). Making sense of developmentally and culturally appropriate practice (DCAP) in early childhood education (Vol. 6). New York, NY: Peter Lang.

Jacobs, A. (2010, May 19). Winter leaves Mongolians a harvest of carcasses. The New York Times. Retrieved from: http://www.nytimes. com/2010/05/20/world/asia/20mongolia.html

Jadambaa, B. (2010). Learning through action. Ulaanbaatar, Mongolia: Countryside School Development. DANIDA.

Lancy, D. F. (2001). Cultural constraints on children's play. Play and Culture Studies, 4, 53-62.

Lancy, D. F. (2002). Cultural constraints on children's play. In J. Roopnarine (Ed.), Conceptual, social-cognitive, and contextual issues in the fields of play (pp. 53-62). Play \& Culture Studies, Vol. 4. Westport, CT: Ablex.

Lancy, D. (2007). Accounting for variability in mother-child play. American Anthropologist, 109, 273-284.

Masten, A. S. (2001). Ordinary magic: Resilience processes in development. American Psychologist, 56(3), 227-238.

Masten, A. S., \& Monn, A. R. (2015). Child and family resilience: A call for integrated science, practice, and professional training. Family Relations, 64(1), 5-21. doi: 10.1111/fare.12103

McCormick, C. M., Kuo, S. I., \& Masten, A. S. (2011). Developmental tasks across the lifespan. In K. L. Fingerman, C. A. Berg, J. Smith, \& T. C. Antonucci (Eds.), Handbook of life span development (pp. 117-140). New York, NY: Springer.

Mongolian Ministry of Education, Culture, and Science. (2013). Early childhood core curriculum. Ulaanbaatar, Mongolia: Mongolian 
Government Printing Office.

Mongolian Ministry of Education, Culture, and Science. (2014). For every child's development. In B. Nasanbayar (Ed.), Kindergarten teachers' handbook (pp. 38-60). Ulaanbaatar, Mongolia: BCI.

Munkhtur, L. (2007). Words that illustrate Mongolian horse appearance, its meaning and structure. Ulaanbaatar, Mongolia: Mongolian State University of Education, Department of Mongolian Studies.

Namjil, T. (2014). Mongolian nomads' culture. Family Mongolia, 2(37), 4-14.

National Statistical Office of Mongolia. (2016). ХYН АМЫН ТОО, аймаг, нийслэл, Байршлаар.

Nielsen, M. (2012). Imitation, pretend play, and childhood: Essential elements in the evolution of human culture? Journal of Comparative Psychology, 126(2), 170-181. doi: 10.1037/a0025168

Onishon Kindergarten. (2013). Mongolian national play. Ulaanbaatar, Mongolia: National Press.

Parten, M. B. (1932). Social participation among pre-school children. The Journal of Abnormal and Social Psychology, 27(3), 243-269.

Pellegrini, A. D., Dupuis, D., \& Smith, P. K. (2007). Play in evolution and development. Developmental Review, 27(2), 261-276. doi: 10.1016/j.dr.2006.09.001

Roopnarine, J., \& Johnson, J. E. (1994). The need to look at play in diverse cultural settings. In J. Roopnarine, J. Johnson, \& F. Hooper (Eds.), Children's play in diverse cultures (pp. 1-8). Albany: SUNY Press.

Roopnarine, J. L., Johnson, J. E., \& Hooper, F. H. (Eds.). (1994). Children's play in diverse cultures. Albany: SUNY Press.

Schwartzman, H. (1978). Transformations: The anthropology of children's play. New York, NY: Plenum.

Sternberg, T. (2010). Unravelling Mongolia’s extreme winter disaster of 2010. Nomadic Peoples, 14(1), 72-86. doi: 10.3167/np.2010.140105

Sumyabaatar, В. (1990). The secret history of Mongolia (Улаанбаатар, Trans.). Ulaanbaatar, Mongolia: BCI.

Sutton-Smith, B. (2001). Reframing the variability of players and play. In S. Reifel (Ed.), Theory in context and out (pp. 27-49). Westport, CT: Ablex.

Sutton-Smith, B. (2009). The ambiguity of play. Cambridge, MA: Harvard University Press.

Tegshjargal, N. (2014). Early childhood teaching management. In J. Batdelger (Ed.), Kindergarten teachers' handbook (2 ${ }^{\text {nd }}$ ed.; pp. $263-$ 266). Ulaanbaatar, Mongolia: Khan Khukhii Zalaa.

Turkle, S. (2007). Evocative objects. Boston, MA: MIT Press.

Turner, N. J., Davidson-Hunt, I. J., \& O'Flaherty, M. (2003). Living on the edge: Ecological and cultural edges as sources of diversity for social-ecological resilience. Human Ecology, 31(3), 439-461. doi: 10.1023/A:1025023906459

Ulziisuren, E. (2011). Factors affecting child mortality (RHS) (Unpublished doctoral dissertation). Mahidol University: Salaya, Thailand.

Ungar, M. (2008). Resilience across cultures. British Journal of Social Work, 38(2), 218-235. doi: 10.1093/bjsw/bcl343

Vygotsky, L. S. (1977). The development of higher psychological functions. Soviet Psychology, 15(3), 60-73. doi: 10.2753/RPO10610405150360

Wickham-Smith, S. (2006). The way of the world. New York, NY: Lexington. 